November 2019

\title{
Rethinking community based strategies to tackle health inequities in South Asia
}

Zulfiqar Ahmed Bhutta

The Aga Khan University, zulfiqar.bhutta@aku.edu

Abhay Bang

SEARCH, Gadchiroli, Maharashtra, India

Kaosar Afsana

BRAC University, Dhaka, Bangladesh

Bishal Gyawali

Aarhus University, Aarhus, Denmark

Mohammed Shafiq Mirzazada

Aga Khan Health Service, Kabul, Afghanistan, shafiq.mirzazada@aku.edu

See next page for additional authors

Follow this and additional works at: https://ecommons.aku.edu/

pakistan_fhs_mc_women_childhealth_paediatr

Part of the Pediatrics Commons, and the Women's Health Commons

\section{Recommended Citation}

Bhutta, Z. A., Bang, A., Afsana, K., Gyawali, B., Mirzazada, M. S., Jayatissa, R. (2019). Rethinking community based strategies to tackle health inequities in South Asia. British medical journal.

Available at: https://ecommons.aku.edu/pakistan_fhs_mc_women_childhealth_paediatr/754 


\section{Authors}

Zulfiqar Ahmed Bhutta, Abhay Bang, Kaosar Afsana, Bishal Gyawali, Mohammed Shafiq Mirzazada, and Renuka Jayatissa 


\title{
Rethinking community based strategies to tackle health inequities in South Asia
}

\author{
A long term strategy is vital to build on the impact of community health workers in achieving universal \\ health coverage, say Zulfiqar Bhutta and colleagues
}

\author{
Zulfiqar A Bhutta founding director ${ }^{1}$ co-director $^{1}$, Abhay Bang director ${ }^{3}$, Kaosar Afsana professor ${ }^{4}$, \\ Bishal Gyawali $P h D$ fellow ${ }^{5}$, Shafiq Mirzazada director ${ }^{6}$, Renuka Jayatissa head ${ }^{7}$ \\ ${ }^{1}$ Centre of Excellence in Women and Child Health, Aga Khan University, Karachi, Pakistan; ${ }^{2}$ Centre for Global Child Health, the Hospital for Sick

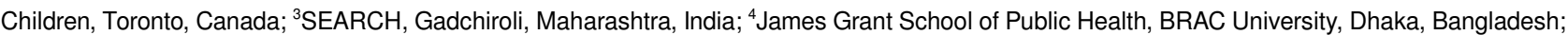 \\ ${ }^{5}$ Department of Public Health, Aarhus University, Aarhus, Denmark; ${ }^{6}$ Academic Projects Afghanistan, Aga Khan University, Kabul, Afghanistan; \\ ${ }^{7}$ Department of Nutrition, Medical Research Institute, Ministry of Health, Colombo, Sri Lanka
}

\begin{abstract}
The world recently celebrated the 40th anniversary of the Alma Ata declaration in 1978 to provide "health for all by the year 2000." That remarkable call for action was not followed by concerted action, however, with much debate on the need for selective or universal primary care. ${ }^{1}$ To accelerate progress in reducing poverty and improving health outcomes, 189 countries signed up to the Millennium Development Goals (MDGs) in September 2000 with two major goals (goal 4 and 5) focused on reducing child and maternal mortality by 2015 . $^{2}$
\end{abstract}

South Asia (comprising Afghanistan, Bangladesh, Bhutan, India, Maldives, Nepal, Pakistan, and Sri Lanka) accounts for a disproportionate number of maternal and under 5 deaths. ${ }^{3}$ Of 2.5 million neonatal deaths in $2017,43 \%$ occurred in South Asia. An estimated $35 \%$ and $31 \%$ respectively of all global under 5 deaths and deaths among children between 5 and 14 years of age also occurred in South Asia. ${ }^{34}$ The corresponding proportion of maternal deaths in 2015 in South Asia was 20\%. ${ }^{5}$ A recent review indicates that Afghanistan, India, and Pakistan have not yet achieved the MDG 4 goals of reducing child mortality. ${ }^{34}$

A major policy response to improve access to healthcare in the region-specifically maternal, newborn, and child health

(MNCH) services-has been shifting tasks to community health workers (CHWs) and community based volunteers ${ }^{67}$ in rural and remote areas. Here, we review the impact of community based strategies and the role of community health workers, and explore opportunities for their long term engagement to tackle health inequities in South Asia.

\section{Health disparities in South Asia}

Progress in child survival within South Asia varies greatly (table 1). ${ }^{34}$ A major challenge, especially in larger countries with diverse populations spread over wide geographies, is one of disparities in $\mathrm{MNCH}$ services $^{2}$ (table 2). The urban and rural differentials are quite stark (figure 1).

Clustering of poverty and deprivation in rural and remote populations is particularly evident in ethnically marginalised indigenous and tribal populations. To illustrate, 104 million tribal people live in India alone ${ }^{8}$ and are subject to enormous disparities in terms of political voice, essential health services, and health and nutrition indicators. ${ }^{39}$ The poor and disempowered are not just restricted to rural and remote populations, but in the case of the slums of mega-cities, are often outside the remit of public services. ${ }^{1011}$

Important health system factors responsible for these inequities relate to lack of trained human resources ${ }^{12}$ and quality of care in health facilities in rural populations. ${ }^{13}$ Community based strategies have emerged against this background to overcome health worker shortage in rural areas, especially those of doctors and nurses, and improve access to health services. ${ }^{67}$

\section{Community based models to tackle inequities}

A range of innovations has been tested to improve outreach in rural and remote populations through community volunteers as well as trained CHWs. These strategies have typically had the explicit objective of improving $\mathrm{MNCH}$ and can be broadly considered as below. 


\section{Outreach services with community health workers}

Some of the earliest experiments involving local health workers and volunteers from the community were undertaken in India, ${ }^{14}$ and provided a template for community outreach and engagement to improve health and nutrition. These experiences led to the formal development of trained community health and nutrition workers, such as the Anganwadi workers deployed across India under the Integrated Child Development Service and Scheme. ${ }^{15}$

It is expected that CHWs have a close understanding and share similar values, ethnic background, language, socioeconomic status, and life experiences as the people they serve-all essential prerequisites for community acceptability. Their role has primarily comprised increasing awareness among communities on health matters, providing antenatal and postnatal care to pregnant women and newborns, supporting immunisation and family planning services, and serving as a link between communities and health facilities. While the actual impact remains uncertain, these initiatives have led to further strategies employing trained CHWs to deliver essential services. Box 1 describes key initiatives employing CHW undertaken in different countries.
Box 1: Community health worker programmes in South Asia India

Under the National Rural Health Mission, some 800000 accredited social health activists were trained in home based newborn care, and 5000 district trainers deployed to cover over 500000 villages across India. While direct evaluation of the impact of this initiative is not available, an independent evaluation of neonatal mortality trends from the sample registration system in India shows that the neonatal mortality rate from infection fell by $66 \%$ (from 11.9 per 1000 livebirths in 2000 to 4.0 per 1000 livebirths in 2015) and the rate from birth asphyxia or trauma fell by $76 \%$ (from 9.0 per 1000 livebirths in 2000 to 2.2 per 1000 livebirths in 2015). ${ }^{16}$ The expert committee on tribal health services in India has recommended having a trained CHW for each tribal hamlet of 250 people. ${ }^{17}$

\section{Bangladesh}

International development organisation BRAC's approach was driven by the principles of primary healthcare and community participation and involved large scale deployment of trained CHWs. The core care providers in BRAC's community health workforce are usually selected from and by the community.

There are two types of trained community health workers, one with a minimum of 10 years of schooling known as Shasthya Kormi (SK), and community volunteers called Shasthya Shebika (SS).

These two cadres are trained in specific competencies, supported by continuous refresher trainings and supervision. The SSs educate communities on preventive practices, identify target populations for specific interventions, offer basic health services, and refer cases to government health facilities as needed. The SKs provide antenatal and postnatal care; reproductive health services, especially adolescent health; and deliver health and nutrition education. Over time, these workers have been shown how to manage a range of conditions, including acute respiratory infections in children ${ }^{18}$; identify and refer symptomatic cases of tuberculosis ${ }^{19}$; and provide essential postnatal and newborn care. ${ }^{20}$ In rural districts, their work has also expanded to include family planning and contraception, diagnosis of pregnancy, and support for deliveries by skilled or trained traditional birth attendants. The average cost of an antenatal visit was BDT 79.2 ( $£ 0.74 ; € 0.83 ; \$ 0.95)$ and the cost of four antenatal care visits, along with pregnancy identification, was BDT $337.5 .{ }^{21}$

\section{Pakistan}

The initiative to deploy trained "Lady Health Workers" (LHWs) was the brainchild of late prime minister Benazir Bhutto who, on returning from the International Conference on Population and Development in 1994, vowed to do something tangible to tackle the rural-urban disparities in Pakistan.

From a modest start, over 50000 LHWs have been deployed across most rural districts of the country within 10 years. They have been trained to provide basic preventive and promotive MNCH services. As such, these LHWs are recruited through a standardised process with selection criteria (age between 18 and 45 years, a local resident with at least 8 years of schooling, preferably married, and being acceptable to the community). Each LHW receives 15 months of basic training at district facilities and ongoing refresher training from accredited district trainers and supervisors. A LHW oversees around 1000 people, or 150 homes, and visits five to seven houses each day. Her responsibilities include health education, community mobilisation for health related matters, antenatal care and referral, immunisation services, provision of family planning, and basic curative care.

In addition to several innovations targeting women and children, in a recent large scale cluster randomised controlled trial in rural Pakistan, LHWs were successfully trained to detect pre-eclampsia and refer these women for facility based care. ${ }^{22}$ The fifth external LHW programme evaluation is planned.

Nepal

The Female Community Health Volunteers (FCHVs) programme was started in the late $1980 \mathrm{~s}^{23}$ Around $50000 \mathrm{FCHVs}$ have been providing family planning, maternal and neonatal health, and child health services. They are often credited for the improvement in maternal health in rural Nepal. The FCHVs are recruited from their own communities through mothers' groups, and trained to provide community health services. They serve as the first point of contact between community members and primary healthcare facilities.

\section{Afghanistan}

The Basic Package of Health Services, introduced in 2002, is delivered at the community level through health posts staffed with one male and one female volunteer CHW covering a population of 1000 to 1500 (around 100 to150 households) ${ }^{24}$ By 2015 around $28000 \mathrm{CHWs}$ were active in rural areas, and nearly half are women. These CHWs play an important role in health education, referral of patients to health facilities, treatment of common childhood ailments, and promoting childhood immunisations. ${ }^{25}$

In a landmark move, the non-governmental organisation (NGO) SEARCH employed trained CHWs in tribal regions of central India for the diagnosis and treatment of childhood pneumonia ${ }^{26}$ and common newborn illnesses. ${ }^{27}$ Trials demonstrated that training CHWs in neonatal resuscitation and linking them to traditional birth attendants and provision of antibiotics halved neonatal mortality related to birth asphyxia and suspected 
neonatal sepsis in the region. This model of home based care was replicated in several rural areas in the state of Maharashtra, ${ }^{28}$ and further incorporated into India's National Rural Health Mission programme in 2011.

In Bangladesh, BRAC, the international development organisation, pioneered the use of health workers at scale in rural populations, with a focus on health, education, and women's empowerment. ${ }^{29}$ Their role in reducing maternal and child mortality in Bangladesh has been widely acknowledged. ${ }^{30}$ In many BRAC areas remarkable gains have been noted, with $89 \%$ of women receiving more than four antenatal visits and $83 \%$ receiving a postnatal visit by the health worker at their home within 48 hours, at no cost. ${ }^{20}$ An evaluation of the BRAC programme in four districts noted a decline in maternal mortality from 183 per 100000 live births in 2010 to 169 per 100000 livebirths in $2011,{ }^{31}$ lower than the national average of 194 per 100000 live births. ${ }^{32}$

These innovations were largely initiated by civic society organisations at both local and national levels and rooted in the principles of social justice and equity. Corresponding investments in the formal health sector remained poor. Perhaps the most audacious deployment of trained public sector CHWs, was in Pakistan with over 90000 trained LHWs deployed in rural Pakistan to provide family planning and primary care services. ${ }^{33}$ Despite challenges in geography and availability of sufficiently educated young women in these regions, the LHW programme achieved almost $70 \%$ coverage in rural districts. A multivariate analysis of the programme showed a positive impact. Households served by LHWs were $11 \%$ points more likely to be using a modern family planning method compared with unserved households; women were $13 \%$ points more likely to have had tetanus toxoid during their pregnancy and although skilled birth attendance rates did not differ, neonatal examinations were $15 \%$ points more likely to have occurred. Children under three years of age were also $15 \%$ points more likely to be fully immunised. ${ }^{34}$

The largest deployment of public sector CHWs in recent years has been through the Accredited Social Health Activists (ASHA) programme ${ }^{35}$ with an estimated 900000 workers all over India. This programme has been instrumental in the gains achieved by the recent conditional cash transfer programme, Janani Suraksha Yojana (JSY), to enhance facility based births. ${ }^{36}$ The uptake of the JSY programme has been varied but it has been associated with a reduction of 3.7 perinatal deaths per 1000 pregnancies and 2.3 neonatal deaths per 1000 livebirths. ${ }^{37}$

\section{Outreach services with formally trained health workers}

The best example is the Preventive Health Care Program of Sri Lanka. It is delivered at the grassroots level through the medical officer of health units, supported by a team comprising public health midwives (PHM), a range of public health supervisors, nurses, and support staff. ${ }^{38}$ The PHMs receive training for 18 months and are the key frontline health workers responsible for $\mathrm{MNCH}$ in their areas. While skill levels have varied, ${ }^{39}$ their role has been critical in reducing maternal mortality in Sri Lanka.

Though limited in scale, a comparable programme of community midwives in Afghanistan is widely credited with improving care $^{40}$ and potentially reducing maternal mortality in rural districts. A cross sectional evaluation (130 688 participants) noted that the maternal mortality rate decreased in both Kabul (by $71 \%$ ) and Ragh regions (by $84 \%$ ) between 2002 and $2011 .^{41}$

\section{Community engagement and participation}

Strategies such as the creation of participatory women's groups supported by community mobilisers provide examples of community engagement and social capital development. A series of large scale trials in Bangladesh, ${ }^{42}$ India, ${ }^{43}$ and Nepal ${ }^{44}$ provide consistent examples of their benefit on maternal and neonatal outcomes and child growth. ${ }^{45}$ A meta-analysis (seven trials, 119 428 births) showed that exposure to women's groups was associated with a $37 \%$ reduction in maternal mortality, a $23 \%$ reduction in neonatal mortality, but with wide heterogeneity. ${ }^{46}$ A more recent meta-analysis has validated the positive effect on behaviours in home deliveries, including the use of safe delivery kits, hand washing by the birth attendant before delivery, and delayed bathing of the newborn for at least 24 hours. ${ }^{47}$ The combination of participatory women's groups with public sector ASHA workers in India has also been associated with $31 \%$ reduction in neonatal mortality over a two year period. $^{48}$

Similar benefits are seen in fragile health systems and conflict settings. A cluster randomised trial in conflict affected tribal areas of Pakistan, consisting of community mobilisation through volunteers and health camps, led to an increase in full immunisation rates and uptake of polio vaccines. ${ }^{49} \mathrm{In}$ Afghanistan, CHWs contributed to improved care seeking patterns and maternal and newborn outcomes in vulnerable populations. ${ }^{50}$

\section{Recent innovations and opportunities for community outreach programmes}

With the success in improving coverage of maternal and child health services, further innovations in expanding the role of community health workers are being tested. In India, SEARCH is attempting to tackle a range of health problems through CHWs, including maternal morbidities, malaria control, stroke prevention, and reducing tobacco consumption in the community. Elsewhere, technology and handheld devices are being employed to help in the routine functioning of $\mathrm{CHW}$ programmes as well as in gathering data.

Going beyond rural settings, BRAC's Manoshi (maternal, neonatal, and child health) programme, launched in 2007, has expanded the role of CHWs to serve in the slums of Dhaka city and up to 10 city corporations. ${ }^{51}$ BRAC also introduced maternity centres in these slums in 2011, where trained birth attendants, supervised by midwives, attend to childbirth. While this programme is at an early stage with limited external evaluations, a third party assessment suggests that four or more antenatal care visits increased from $27 \%$ to $52 \%$, and facility based deliveries from $15 \%$ to $65 \%$, in the targeted slums between 2007 and 2011. ${ }^{52}$

Some of the most exciting opportunities are the potential role that these frontline workers could play in tackling the unmet need of non-communicable diseases (NCDs) in their communities, such as through prevention and the early detection and management of type 2 diabetes and hypertension.$^{53}$ South Asia has seen a rapid rise in NCDs in recent years, and combined with communicable diseases, it poses a heavy double burden. ${ }^{54}$ CHWs could potentially undertake a range of activities, including:

- health promotion to reduce risk factors for NCDs across all age groups, including adolescents

- screening households and targeted health promotion for NCDs and mental illnesses (including depression) using simple non-invasive tools 
- referring those who are at high risk of NCDs to the nearest health facility

- education on drug adherence

- recording, reporting, and follow-up.

More specifically, CHWs could be trained to measure blood pressure and blood glucose if provided with appropriate equipment. ${ }^{55}$ Such strategies have been shown to improve detection of hypertension in studies from $\mathrm{Nepal}^{56}$ and Pakistan. ${ }^{57}$ It is thus anticipated that CHWs can be innovatively involved to improve NCD management in low resource settings, and facilitate change in health behaviours and outcomes in the community.

\section{The way forward}

While community based primary care approaches using CHWs, volunteers, and participatory processes have been helpful in reducing the equity gap and increasing access in rural and marginalised populations, South Asia needs a long term strategy to optimise their impact. Much of the evidence on the role of CHWs in reaching rural and remote populations is derived from small scale efficacy trials or well controlled cluster randomised trials. Few studies have evaluated the effectiveness of CHWs within large public sector programmes or those deployed at scale. Where such studies have been undertaken, the general impact has been lower than that observed in research settings. ${ }^{58}$ More information is needed on CHW retention, effectiveness, community engagement, and the long term sustainability of such programmes. To be successful, CHW programmes need appropriate planning, active leadership, secure financing, and community support. Some of these gaps have been underscored in the recent World Health Organization guidelines to optimise the performance of CHW programmes. ${ }^{59}$

Standardised selection and training criteria and a clear long term strategy as to their role in the future will be important. The community health approach has immense implications for tackling primary healthcare gaps, provided frontline workers are well trained and supported through a continuous focus on improvement in quality, supportive supervision, and incentives. ${ }^{60}$ Their role in preventive and promotive care is critical. CHWs could see their utility increase over time as community mobilisers and promoters of preventive and care strategies related to NCDs. Their potential role in screening for mental health disorders and promoting sexual and reproductive health also needs to be explored. Such a strategy of gradually transitioning a CHW programme of Behvarz workers was successfully employed in $\operatorname{Iran}^{61}$ and could well be a game changer for the region in tackling the challenge of chronic diseases. The potential impact of CHW programmes on long term human capital and intergenerational benefits is considerable and poorly recognised by policy makers.

For a functional primary care system, such outreach workers should be backed up by a robust supervisory and referral system for quality care within health facilities as needed. Achieving the Sustainable Development Goals and a universal healthcare strategy that mandates equal access to all will require the deployment of a trained workforce, especially qualified physicians, nurses, and midwives across the health system, supported by the financial mechanisms to ensure universal healthcare. It is estimated that 7.2 million health workers are needed to provide essential services worldwide. ${ }^{62} \mathrm{CHWs}$ with some formal training are an important group therein. ${ }^{63}$ Developing transition plans will be critical to ensure that such CHW and community volunteer programmes are fully integrated within the health system with a long term role for their engagement.

In the long run, South Asia needs a clear strategy for developing, deploying, and retaining properly trained physicians, nurses, and midwives across all regions, avoiding the ethical challenge of persistent inequities in the health workforce and relegation of large sections of rural populations to the care of community health workers alone.

Key messages

Community health workers play a critical role in overcoming health workforce shortages and have led to measurable impact in improving maternal and child health in rural parts of South Asia

Appropriate planning, active leadership, secure financing, and community support are essential for their success

A long term strategy for their engagement must include a plan to transition and expand their role to meet evolving health needs while ensuring consistent support through a robust primary healthcare system

Author contributions: $Z A B$ conceived of the design and provenance of the review, coordinated the inputs from other authors, and wrote the first draft. $A B$ contributed to the design of the review. $B G, K A, R K$, and $S M$ contributed to the literature search. $K A, R K$, and $S M$ contributed to data collection. KA contributed to data analysis. $B G, K A$, and $S M$ contributed to data interpretation. $A B, B G$, and $R K$ contributed to critical revision of the paper. All authors contributed to the content and writing process and approved the final version for submission.

We thank Mahdis Kamali and Arjumand Rizvi for collating the information summarised in the tables and figure. Grace Belayneh graciously assisted with much of the coordination.

Competing interests: We have read and understood BMJ policy on declaration of interests and have no relevant interests to declare.

Provenance and peer review: Commissioned; externally peer reviewed.

Bhutta ZA, Atun R, Ladher N, Abbasi K. Alma Ata and primary healthcare: back to the future. BMJ 2018:363:k4433. 10.1136/bmi.k4433 30348680

2 United Nations. Millennium Development Goals. www.un.org/millenniumgoals.

3 Akseer N, Kamali M, Arifeen SE, et al. Progress in maternal and child health: how has South Asia fared?BMJ 2017;357:j1608. 10.1136/bmj.j1608 28400481

4 United Nations Interagency Group for Child Mortality Estimation. Levels and trends in child mortality report 2018. UNICEF 2018. www.unicef.org/publications/index_103264. child mort.

5 WHO, UNICEF, UNFPA, World Bank Group and the United Nations Population Division. Trends in maternal mortality: 1990 to 2015: estimates by WHO, UNICEF, UNFPA, World Bank Group and the United Nations Population Division. 2015. www.who.int/ reproductivehealth/publications/monitoring/maternal-mortality-2015/en.

6 Bhutta ZA, Lassi Z, Pariyo G, Huicho L. Global experience of community health workers for delivery of health related Millennium Development Goals: a systematic review, country case studies, and recommendations for integration into national health systems. WHO. 2010 www.who.int/workforcealliance/knowledge/resources/chwreport/en.

7 Schneider H, Okello D, Lehmann U. The global pendulum swing towards community health workers in low- and middle-income countries: a scoping review of trends, geographical distribution and programmatic orientations, 2005 to 2014. Hum Resour Health 2016;14:65. 10.1186/s12960-016-0163-2 27784298

8 Census Info India. 2011. www.dataforall.org/dashboard/censusinfo.

9 Bang A, Jhalani Manoj, Angami N, et al. Tribal health in India: report of the Expert Committee on Tribal Health. Ministry of Health and Family Welfare, Government of India. 2018. http://nhm.gov.in/nrhm-updates/598-report-of-the-expert-committee-on-tribal-health. $\mathrm{html}$

10 Megacities in South Asia (BMJ current issue; tech ed to add)

11 Adams AM, Nambiar D, Siddiqi S, Alam BB, Reddy S. Advancing universal health coverage in South Asian cities: a framework. BMJ 2018;363:k4905. 10.1136/bmj.k4905.

12 GBD 2015 Healthcare Access and Quality Collaborators. Healthcare Access and Quality Index based on mortality from causes amenable to personal health care in 195 countries and territories, 1990-2015: a novel analysis from the Global Burden of Disease Study 2015. Lancet 2017;390:231-66. 10.1016/S0140-6736(17)30818-8 28528753

13 Kruk ME, Gage AD, Joseph NT, Danaei G, García-Saisó S, Salomon JA. Mortality due to low-quality health systems in the universal health coverage era: a systematic analysis of amenable deaths in 137 countries. Lancet 2018;392:2203-12. 10.1016/S0140-6736(18)31668-4 30195398

14 Taylor CE, Kielmann AA, DeSweemer C, et al. The Narangwal experiment on interactions of nutrition and infections : I. Project design and effects upon growth. Indian J Med Res 1978:68(Suppl):1-20.751919

15 Lal S. Monitoring of severely malnourished children and domiciliary management in rural settings by Anganwadi workers under integrated child development service \& scheme. Indian Pediatr 1982;19:409-13. 7141655

16 Million Death Study Collaborators. Changes in cause-specific neonatal and 1-59-month child mortality in India from 2000 to 2015: a nationally representative survey. Lancet 2017;390:1972-80. 10.1016/S0140-6736(17)32162-1 28939096 
17 Report of Expert Committee on Tribal Health. 2013. http://nhm.gov.in/nrhm-updates/598report-of-the-expert-committee-on-tribal-health html.

18 Hadi A. Management of acute respiratory infections by community health volunteers: experience of Bangladesh Rural Advancement Committee (BRAC). Bull World Health Organ 2003;81:183-9.12764514

19 Islam MA, Wakai S, Ishikawa N, Chowdhury AMR, Vaughan JP. Cost-effectiveness of community health workers in tuberculosis control in Bangladesh. Bull World Health Organ 2002:80:445-50.12132000

20 Rahman M, Jhohura FT, Mistry SK, et al. Assessing Community Based Improved Maternal Neonatal Child Survival (IMNCS) Program in Rural Bangladesh. PLoS One 2015;10:e0136898. 10.1371/journal.pone.0136898 26340672

21 Khan MN, Quayyum Z, Quayyum T, Nasreen H, Mahmud SN, Ensor T. Costs of providing maternal, newborn and child healthcare: estimates from BRAC's IMNCS programme in rural Bangladesh. 2012. http://research.brac.net/workingpapers/Working_Paper_31.pdf.

22 Khowaja AR, Qureshi RN, Sawchuck D, et alCLIP Working Group. The feasibility of community level interventions for pre-eclampsia in South Asia and Sub-Saharan Africa: a mixed-methods design. Reprod Health 2016;13(Suppl 1):56. 10.1186/s12978-016-0133-0 27357579

23 World Health Organization. Female community health volunteers. 2010.

24 Najafizada SA, Labonté R, Bourgeault IL. Community health workers of Afghanistan: a qualitative study of a national program. Confl Health 2014;8:26. 10.1186/1752-1505-8-26 25904976

25 Edward A, Branchini C, Aitken I, Roach M, Osei-Bonsu K, Arwal SH. Toward universal coverage in Afghanistan: A multi-stakeholder assessment of capacity investments in the community health worker system. Soc Sci Med 2015;145:173-83. 10.1016/. socscimed.2015.06.01126141453

26 Bang AT, Bang RA, Tale O, et al. Reduction in pneumonia mortality and total childhood mortality by means of community-based intervention trial in Gadchiroli, India. Lancet 1990;336:201-6. 10.1016/0140-6736(90)91733-Q 1973770

27 Bang AT, Bang RA, Baitule SB, Reddy MH, Deshmukh MD. Effect of home-based neonatal care and management of sepsis on neonatal mortality: field trial in rural India. Lancet 1999;354:1955-61. 10.1016/S0140-6736(99)03046-9 10622298

28 Report of the evaluation of Ankur project: Society for Education, Action and Research in Community Health, Gadchiroli, India. 2006. http://srujan.info/resource/50/hbnc-ankur.pdf.

29 BRAC. 2017 annual report. 2017. www.brac.net/sites/default/files/annual-report/2017/ BRAC-AR-2017e.pdf.

30 El Arifeen S, Christou A, Reichenbach L, et al. Community-based approaches and partnerships: innovations in health-service delivery in Bangladesh. Lancet 2013:382:2012-26. 10.1016/S0140-6736(13)62149-2 24268607

31 Nasreen HE, Afsana K. Maternal, neonatal and child health. In: Hossain M, etal , eds. Driving Development. A Story of BRAC's Evolution and Effectiveness. University Press Ltd, 2016.

32 National Institute of Population Research and Training. MEASURE Evaluation, and icddr,b. Bangladesh maternal mortality and health care survey 2010. 2012. www. measureevaluation.org/resources/publications/tr-12-87.

33 Hafeez A, Mohamud BK, Shiekh MR, Shah SA, Jooma R. Lady health workers programme in Pakistan: challenges, achievements and the way forward. J Pak Med Assoc 2011;61:210-5.21465929

34 Management OP. Lady Health Workers programme: external evaluation of the Nationa programme for Family Planning and Primary Health Care: summary of results. 2009. www.opml.co.uk/files/Publications/6241-evaluating-lady-health-worker-programme/lhw4th-evaluation-summary-of-results.pdf?noredirect $=1$.

35 Accredited Social Health Activist (ASHA) - the trained woman community health volunteer. Nurs J India 2005;96:252-4. 16572976

$36 \mathrm{Ng} \mathrm{M}$, Misra A, Diwan V, Agnani M, Levin-Rector A, De Costa A. An assessment of the impact of the JSY cash transfer program on maternal mortality reduction in Madhya Pradesh, India. Glob Health Action 2014;7:24939. 10.3402/gha.v7.24939 25476929

37 Lim SS, Dandona L, Hoisington JA, James SL, Hogan MC, Gakidou E. India's Janani Suraksha Yojana, a conditional cash transfer programme to increase births in health facilities: an impact evaluation. Lancet 2010;375:2009-23. 10.1016/S0140-6736(10)60744-1 20569841

38 Haththotuwa R, Senanayake L, Senarath U, Attygalle D. Models of care that have reduced maternal mortality and morbidity in Sri Lanka. Int J Gynaecol Obstet 2012;119(Suppl 1):S45-9. 10.1016/.jijgo.2012.03.016 22883911

39 Gunathunga W, Fernando DN. Assessment of community maternal care performance of public health midwives of a province in Sri Lanka: a multi-method approach. Southeast Asian J Trop Med Public Health 2000;31:310-8. 11127332

40 Zainullah P, Ansari N, Yari K, et al. Establishing midwifery in low-resource settings: guidance from a mixed-methods evaluation of the Afghanistan midwifery education program. Midwifery 2014:30:1056-62. 10.1016/j.midw.2013.10.026 24290947

41 Bartlett L, LeFevre A, Zimmerman L, et al. Progress and inequities in maternal mortality in Afghanistan (RAMOS-II): a retrospective observational study. Lancet Glob Health 2017;5:e545-55. 10.1016/S2214-109X(17)30139-0 28395847

$42 \mathrm{Azad} \mathrm{K}$, Barnett S, Banerjee B, et al. Effect of scaling up women's groups on birth outcomes in three rural districts in Bangladesh: a cluster-randomised controlled trial. Lancet 2010;375:1193-202. 10.1016/S0140-6736(10)60142-0 20207412

43 Tripathy P, Nair N, Barnett S, et al. Effect of a participatory intervention with women's groups on birth outcomes and maternal depression in Jharkhand and Orissa, India: a cluster-randomised controlled trial. Lancet 2010;375:1182-92.

10.1016/S0140-6736(09)62042-0 20207411

44 Manandhar DS, Osrin D, Shrestha BP, et alMembers of the MIRA Makwanpur trial team. Effect of a participatory intervention with women's groups on birth outcomes in Nepal: cluster-randomised controlled trial. Lancet 2004;364:970-9. 10.1016/S0140-6736(04)17021-9 15364188

45 Nair N, Tripathy P, Sachdev HS, et al. Effect of participatory women's groups and counselling through home visits on children's linear growth in rural eastern India (CARING trial): a cluster-randomised controlled trial. Lancet Glob Health 2017;5:e1004-16. 10.1016/S2214-109X(17)30339-X 28911749

46 Prost A, Colbourn T, Seward N, et al. Women's groups practising participatory learning and action to improve maternal and newborn health in low-resource settings: a systematic review and meta-analysis. Lancet 2013;381:1736-46.

10.1016/S0140-6736(13)60685-6 23683640

47 Seward N, Neuman M, Colbourn T, et al. Effects of women's groups practising participatory learning and action on preventive and care-seeking behaviours to reduce neonatal mortality: A meta-analysis of cluster-randomised trials. PLOS Med 2017;14:e1002467. 10.1371/journal.pmed.1002467 29206833

48 Tripathy P, Nair N, Sinha R, et al. Effect of participatory women's groups facilitated by Accredited Social Health Activists on birth outcomes in rural eastern India: a cluster-randomised controlled trial. Lancet Glob Health 2016;4:e119-28. 10.1016/S2214-109X(15)00287-9 26823213

49 Habib MA, Soofi S, Cousens S, et al. Community engagement and integrated health and polio immunisation campaigns in conflict-affected areas of Pakistan: a cluster randomised controlled trial. Lancet Glob Health 2017;5:e593-603.

10.1016/S2214-109X(17)30184-5 28495264

50 Edmond KM, Yousufi K, Anwari Z, et al. Can community health worker home visiting improve care-seeking and maternal and newborn care practices in fragile states such as Afghanistan? A population-based intervention study. BMC Med 2018;16:106 10.1186/s12916-018-1092-9 29983113

51 Afsana $\mathrm{K}$, Roy $\mathrm{T}$, Chowdhury RH, et al. Manoshi: a community health solution in urban Bangladesh. Manoshi Annual Report 2007-12. Health, Nutrition \& Population Programme, BRAC, 2013.

52 Alam N, Begum D, Ahmed SM, Streatfield PK, BRAC, International Centre for Diarrhoeal Disease Research Bangladesh. Manoshi community health solutions in Bangladesh: impact evaluation surveys in Dhaka urban slums 2007, 2009, and 2011. http://dspace. icddrb.org/jspui/bitstream/123456789/6779/1/Manoshi\%20Evaluation\%20Surveys\% 20Report11 Final.pdf.

53 Gyawali B, Bloch J, Vaidya A, Kallestrup P. Community-based interventions for prevention of Type 2 diabetes in low- and middle-income countries: a systematic review. Health Promot Int 2018. 10.1093/heapro/day081. 30329052

54 Misra A, Tandon N, Ebrahim S, et al. Diabetes, cardiovascular disease, and chronic kidney disease in South Asia: current status and future directions. BMJ 2017;357:j1420. 10.1136/bmj.j1420 28400361

55 Gyawali B, Mishra SR, Neupane D, Vaidya A, Sandbæk A, Kallestrup P. Diabetes management training for female community health volunteers in Western Nepal: an implementation experience. BMC Public Health 2018;18:641. 10.1186/s12889-018-5562-y 29783961

56 Neupane D, McLachlan CS, Mishra SR, et al. Effectiveness of a lifestyle intervention led by female community health volunteers versus usual care in blood pressure reduction (COBIN): an open-label, cluster-randomised trial. Lancet Glob Health 2018;6:e66-73. 10.1016/S2214-109X(17)30411-4 29241617

57 Jafar TH, Hatcher J, Poulter N, et alHypertension Research Group. Community-based interventions to promote blood pressure control in a developing country: a cluster randomized trial. Ann Intern Med 2009;151:593-601. 10.7326/0003-4819-151-9-200911030-00004 19884620

58 Kirkwood BR, Manu A, ten Asbroek AH, et al. Effect of the Newhints home-visits intervention on neonatal mortality rate and care practices in Ghana: a cluster randomised controlled trial. Lancet 2013;381:2184-92. 10.1016/S0140-6736(13)60095-1 23578528

59 World Health Organization. WHO guideline on health policy and system support to optimize community health worker programmes. 2018. http://apps.who.int/iris/bitstream/handle/ 10665/275474/9789241550369-eng.pdf?ua=1\&ua=1.

60 Salehi AS, Saljuqi ATK, Akseer N, Rao K, Coe K. Factors influencing performance by contracted non-state providers implementing a basic package of health services in Afghanistan. Int J Equity Health 2018;17:128. 10.1186/s12939-018-0847-4 30286770

61 Aghajanian A, Mehryar AH, Ahmadnia S, Kazemipour S. Impact of the rural health development programme in the Islamic Republic of Iran on rural-urban disparities in health indicators. World Hosp Health Serv 2008;44:10-5. 19181021

62 One Million Community Health Workers Campaign. Data for decision making series. http: //1millionhealthworkers.org/data-for-decision-making.

63 Singh P, Sachs JD. 1 million community health workers in sub-Saharan Africa by 2015 Lancet 2013;382:363-5. 10.1016/S0140-6736(12)62002-9 23541538

Published by the BMJ Publishing Group Limited. For permission to use (where not already granted under a licence) please go to http://group.bmj.com/group/rights-licensing/ permissions 


\section{Tables}

Table 1| Maternal mortality ratio (deaths per 100000 live births), neonatal, post-neonatal, and under 5 mortality rate (per 1000 live births) in South Asia

\begin{tabular}{|c|c|c|c|c|c|c|c|c|c|c|c|c|c|}
\hline \multirow[b]{2}{*}{ Country } & \multicolumn{3}{|c|}{ Maternal mortality ratio } & \multicolumn{3}{|c|}{ Neonatal mortality rate } & \multicolumn{3}{|c|}{ Post-neonatal mortality rate } & \multicolumn{4}{|c|}{ Under 5 mortality rate } \\
\hline & 1990 & 2015 & $\begin{array}{l}\text { Estimated ARR } \\
(95 \% \mathrm{Cl}) \\
\text { maternal } \\
\text { mortality }\end{array}$ & 1990 & 2017 & $\begin{array}{l}\text { Estimated ARR } \\
(95 \% \mathrm{Cl}) \text { neonatal } \\
\text { mortality }\end{array}$ & 1990 & 2017 & $\begin{array}{l}\text { Estimated ARR } \\
(95 \% \mathrm{Cl}) \\
\text { post-neonatal } \\
\text { mortality }\end{array}$ & 1990 & 2013 & 2017 & $\begin{array}{l}\text { Estimated ARR } \\
(95 \% \mathrm{Cl}) \text { under } \\
5 \text { mortality }\end{array}$ \\
\hline Maldives & 677 & 68 & $8.90(8.00-9.84)$ & 43 & 5 & $6.60(5.81-7.38)$ & 100 & 29 & $7.90(6.68-9.10)$ & 94 & 10 & 8 & $9.2(8.1-10.2)$ \\
\hline Bhutan & 945 & 148 & $7.18(7.08-7.27)$ & 43 & 17 & $3.27(3.09-3.45)$ & 75 & 31 & $5.79(5.20-6.37)$ & 128 & 36 & 31 & $5.3(3.8-6.8)$ \\
\hline Afghanistan & 1340 & 396 & $4.86(4.38-5.34)$ & 75 & 39 & $2.36(2.26-2.45)$ & 85 & 14 & $4.24(3.93-4.54)$ & 175 & 97 & 68 & $3.5(2.6-4.5)$ \\
\hline India & 556 & 174 & $4.79(4.66-4.93)$ & 57 & 24 & $3.07(2.91-3.23)$ & 69 & 15 & $5.06(4.62-5.50)$ & 126 & 53 & 39 & $4.3(3.9-4.7)$ \\
\hline Nepal & 901 & 258 & $4.57(4.44-4.70)$ & 59 & 21 & 3.61 (3.39-3.83) & 80 & 14 & $5.85(5.25-6.45)$ & 140 & 40 & 34 & $5.3(4.5-6.1)$ \\
\hline Bangladesh & 569 & 176 & $4.50(4.28-4.72)$ & 64 & 18 & $4.33(4.01-4.65)$ & 81 & 13 & $5.67(5.11-6.22)$ & 144 & 41 & 32 & $5.5(5.1-5.9)$ \\
\hline Sri Lanka & 75 & 30 & 4.03 (3.83-4.23) & 13 & 6 & $2.76(2.63-2.89)$ & 51 & 3 & $3.44(3.24-3.64)$ & 21 & 10 & 9 & $3.3(2.7-3.8)$ \\
\hline Pakistan & 431 & 178 & $3.53(3.49-3.57)$ & 64 & 44 & $1.38(1.34-1.41)$ & 8 & 3 & $3.13(2.96-3.29)$ & 139 & 86 & 75 & $2.3(1.3-2.4)$ \\
\hline
\end{tabular}




\begin{tabular}{|c|c|c|c|c|c|c|c|c|}
\hline $\begin{array}{l}\text { Coverage } \\
\text { indicators } \\
\text { (urban/rural) }\end{array}$ & $\begin{array}{l}\text { Afghanistan } \\
\text { (DHS 2015) }\end{array}$ & $\begin{array}{l}\text { Bangladesh } \\
\text { (DHS 2014) }\end{array}$ & $\begin{array}{l}\text { Bhutan (DHS } \\
\text { 2010) }\end{array}$ & $\begin{array}{l}\text { India (DHS } \\
\text { 2015) }\end{array}$ & $\begin{array}{l}\text { Maldives (DHS } \\
\text { 2009) }\end{array}$ & $\begin{array}{l}\text { Nepal (DHS } \\
\text { 2016) }\end{array}$ & $\begin{array}{l}\text { Pakistan (DHS } \\
\text { 2012) }\end{array}$ & $\begin{array}{l}\text { Sri Lanka } \\
\text { (census/DHS } \\
\text { 2016) }\end{array}$ \\
\hline \multirow{2}{*}{$\begin{array}{l}\text { Family planning } \\
\text { needs satisfied }\end{array}$} & 49.0 & 74.4 & 87.3 & 73.9 & 42.2 & 57.0 & 51.7 & \multirow[t]{2}{*}{-} \\
\hline & 39.3 & 71.9 & 85.2 & 70.9 & 42.3 & 54.5 & 44.3 & \\
\hline \multirow{2}{*}{$\begin{array}{l}\text { Antenatal care, } \\
\text { four visits }\end{array}$} & 32.7 & 45.5 & 87.1 & 66.1 & 81.4 & 75.6 & 61.4 & \multirow[t]{2}{*}{-} \\
\hline & 13.3 & 26.1 & 73.3 & 44.6 & 87.2 & 64.2 & 27.0 & \\
\hline \multirow{2}{*}{$\begin{array}{l}\text { Tetanus toxoid in } \\
\text { pregnancy }\end{array}$} & 30.6 & \multirow[t]{2}{*}{-} & 51.7 & 84.4 & 76.6 & 67.6 & 69.5 & 94.7 \\
\hline & 34.4 & & 48.5 & 82.4 & 52.0 & 63.4 & 53.8 & 97.2 \\
\hline \multirow{2}{*}{$\begin{array}{l}\text { Skilled birth } \\
\text { attendance }\end{array}$} & 81.3 & 60.5 & 89.4 & 90.9 & 99.8 & 71.4 & 73.4 & \multirow[t]{2}{*}{-} \\
\hline & 45.8 & 35.6 & 54.2 & 80.4 & 95.5 & 52.8 & 49.3 & \\
\hline \multirow{2}{*}{$\begin{array}{l}\text { Postnatal care } \\
\text { women }\end{array}$} & 52.0 & 75.7 & \multirow[t]{2}{*}{-} & 73.4 & 74.0 & 63.9 & 73.9 & 99 \\
\hline & 36.1 & 54.6 & & 62.4 & 68.8 & 48.4 & 54.7 & 99.3 \\
\hline \multirow{2}{*}{$\begin{array}{l}\text { Postnatal care } \\
\text { baby }\end{array}$} & 12.7 & 70.6 & \multirow[t]{2}{*}{-} & 28.4 & \multirow[t]{2}{*}{-} & 63.4 & 52.4 & \multirow[t]{2}{*}{-} \\
\hline & 8.3 & 48.9 & & 26.9 & & 49.1 & 38.9 & \\
\hline \multirow{2}{*}{$\begin{array}{l}\text { Early initiation } \\
\text { breastfeeding }\end{array}$} & 37.7 & 45.3 & 61.3 & 42.9 & 54.9 & 57.0 & 17.9 & 87 \\
\hline & 41.9 & 52.8 & 58.1 & 41.0 & 63.0 & 52.5 & 18.1 & 91.2 \\
\hline \multirow{2}{*}{$\begin{array}{l}\text { Exclusive } \\
\text { breastfeeding }\end{array}$} & 41.4 & 54.1 & 57.4 & 52.1 & \multirow[t]{2}{*}{-} & 63.2 & 35.5 & \multirow[t]{2}{*}{-} \\
\hline & 44.0 & 55.7 & 44.5 & 55.9 & & 69.5 & 38.7 & \\
\hline \multirow{2}{*}{$\begin{array}{l}\text { Continued } \\
\text { breastfeeding }\end{array}$} & 77.9 & 92.0 & 90.8 & 80.3 & 61.7 & 97.6 & 75.1 & \multirow[t]{2}{*}{-} \\
\hline & 78.5 & 97.1 & 93.5 & 88.4 & 84.2 & 98.7 & 83.3 & \\
\hline \multirow[t]{2}{*}{ DPT3 vaccine } & 68.2 & 93.6 & \multirow[t]{2}{*}{-} & 80.5 & 98.2 & 86.0 & 79.1 & 91.9 \\
\hline & 55.2 & 90.4 & & 78.0 & 97.7 & 86.6 & 59.1 & 96.9 \\
\hline \multirow[t]{2}{*}{ Measles } & 68.1 & 90.0 & \multirow[t]{2}{*}{-} & 83.2 & 93.5 & 91.2 & 74.3 & 94 \\
\hline & 57.9 & 84.8 & & 80.3 & 95.0 & 89.5 & 55.6 & 97.7 \\
\hline \multirow{2}{*}{$\begin{array}{l}\text { Vitamin A } \\
\text { supplementation }\end{array}$} & 47.6 & 65.3 & \multirow[t]{2}{*}{-} & 62.0 & 27.4 & 82.1 & 68.0 & 52.9 \\
\hline & 47.5 & 61.0 & & 57.9 & 56.7 & 82.9 & 73.8 & 55.8 \\
\hline \multirow{2}{*}{$\begin{array}{l}\text { Care seeking for } \\
\text { pneumonia }\end{array}$} & 65.1 & 52.1 & 74.1 & 86.2 & \multirow[t]{2}{*}{-} & 63.7 & 75.1 & - \\
\hline & 60.3 & 39.3 & 74.2 & 75.5 & & 47.5 & 60.4 & \\
\hline ORS use in & 43.7 & 83.4 & 64.3 & 58.5 & - & 35.8 & 41.5 & 47.3 \\
\hline diarrhoea & 47.1 & 74.8 & 59.5 & 47.9 & & 38.3 & 36.6 & 55.3 \\
\hline Improved water & 85.8 & 98.4 & 99.6 & 91.4 & 99.4 & 93.9 & 80.8 & 98.7 \\
\hline & 59.9 & 97.0 & 94.8 & 89.3 & 97.4 & 96.3 & 53.1 & 91 \\
\hline Improved & 54.6 & 52.2 & 77.9 & 71.1 & 97.5 & 64.8 & 86.8 & 91 \\
\hline & 16.9 & 46.2 & 51.0 & 37.2 & 93.2 & 64.3 & 46.2 & 90 \\
\hline
\end{tabular}

Note: FPS= demand for family planning satisfied with modern methods, ANC4= antenatal care (at least four visits), Tetanus toxoid= 2 shots during pregnancy, $\mathrm{SBA}=$ skilled birth attendant, Postnatal care women= postnatal care for mothers within 2 days after delivery, Postnatal care baby= postnatal care for babies within 2 days of birth, Early initiation breastfeeding= early initiation of breastfeeding (within 1 hour of birth), Exclusively breastfed= breastfed exclusively within 6 months, Continued breastfeeding = continued breastfeeding (year 1), DPT3= diphtheria-tetanus-pertussis immunisation (three doses), Measles $=$ measles immunisation (first dose), Vitamin A supplementation= vitamin A supplementation (two doses), Care seeking for pneumonia= sought treatment for suspected pneumonia in the past two weeks, ORS= oral rehydration solution for diarrhoea in the past 2 weeks, Improved water= population using basic drinking water services, Improved sanitation= population using basic sanitation services (non-shared) 


\section{Figure}

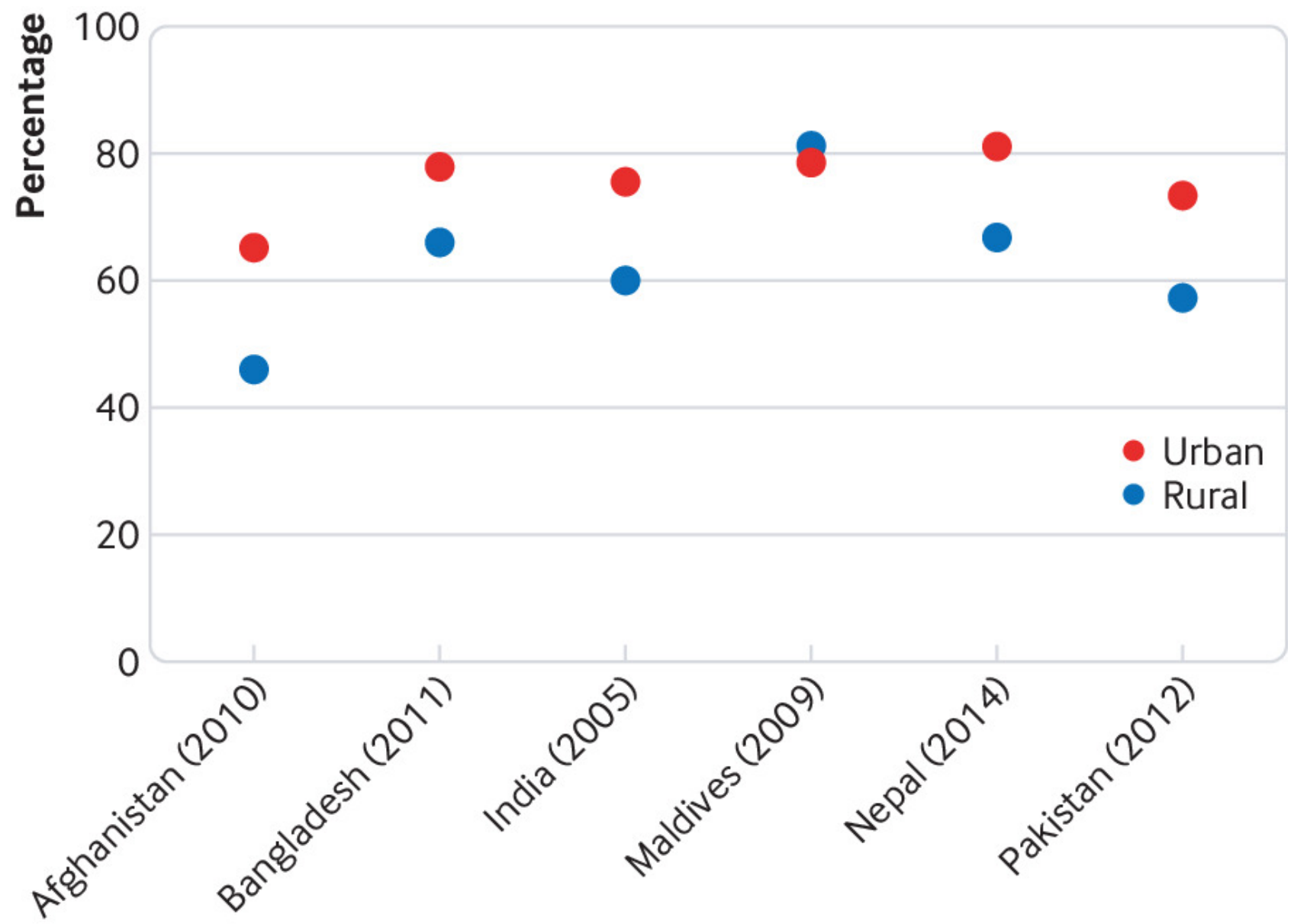

Fig 1 Urban and rural differentials in Composite Coverage Indicator for countries in South Asia 